\title{
Expansão por umidade de revestimentos cerâmicos incorporados com residuos de granito e caulim
}

\author{
(Moisture expansion of ceramic tiles produced \\ using kaolin and granite wastes )
}

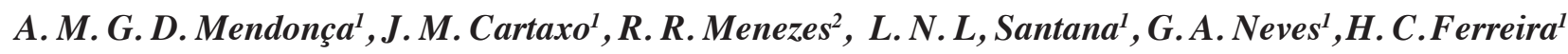 \\ ${ }^{1}$ Unidade Acadêmica de Engenharia de Materiais, Universidade Federal de Campina Grande, Av. Aprígio \\ Veloso 882, Campina Grande, PB 58109-970 \\ ${ }^{2}$ Departamento de Engenharia de Materiais, Universidade Federal da Paraíba, Cidade Universitária \\ J. Pessoa, PB 58051-900 \\ ana.duartemendonca@gmail.com,gelmires@dema.ufcg.edu.br,lisiane@dema.ufcg.edu.br
}

\begin{abstract}
Resumo
Expansão por umidade (EPU) é o aumento das dimensões dos materiais cerâmicos em virtude da adsorção de água. A EPU geralmente ocorre lentamente e é relativamente pequena, mas, mesmo assim, pode comprometer a aderência das placas cerâmicas ao contrapiso, levar ao gretamento do vidrado e conduzir ao aparecimento de trincas em tijolos. Neste trabalho empregaram-se massas incorporadas com resíduos de caulim e de granito objetivando estudar a EPU de revestimentos cerâmicos. As matériasprimas foram beneficiadas e submetidas às caracterizações físicas e mineralógicas através de ensaios de análise granulométrica por difração a laser, análise química, análise termodiferencial, termogravimétrica e difração de raios X. Os resultados mostraram que os resíduos de caulim e de granito podem ser utilizados como matéria-prima cerâmica alternativa, pois apresentam características similares às matérias-primas cerâmicas convencionais, permitindo a obtenção de peças com resultados de EPU satisfatórios quando comparado ao valor limite de $0,6 \mathrm{~mm} / \mathrm{m}(0,06 \%)$ proposto pela ABNT para revestimentos cerâmicos, notadamente em composições com teores de até $20 \%$ de resíduos, a temperaturas superiores a $1000{ }^{\circ} \mathrm{C}$.
\end{abstract}

Palavras-chave: expansão por umidade, resíduos, revestimentos cerâmicos.

\begin{abstract}
Moisture expansion (ME) is the term used to describe the expansion of ceramic materials due to the adsorption of water. ME usually occurs slowly and is relatively small, but, it can damage the ceramic tiles adhesion to the underlayment, craze the glaze and lead to the development of cracks on ceramics bricks. In this work kaolin and granite wastes were incorporated in ceramic compositions aiming study their influence on the ME of ceramic tiles. Raw materials were processed and submitted to characterization: physical and mineralogical by laser diffraction particle size analysis, chemical analysis, thermodifferential and thermogravimetric analysis and X-ray diffraction. Results showed that kaolin and granite wastes can be incorporated in ceramic composition because display characteristics similar to conventional not plastic ceramic materials, providing satisfactory ME results when compared to the ME limit value of $0.6 \mathrm{~mm} / \mathrm{m}(0.06 \%)$ indicated by the ABNT for ceramic tiles. Compositions containing up to $20 \%$ of waste can be produced when firing above $1000{ }^{\circ} \mathrm{C}$
\end{abstract}

Keywords: moisture expansion, waste, ceramic tiles.

\section{INTRODUÇÃO}

Expansão por umidade (EPU) é o termo geralmente utilizado para designar o aumento das dimensões dos materiais cerâmicos, notadamente tijolos, telhas e revestimentos cerâmicos, ocasionados pela adsorção de água. Essa expansão geralmente ocorre lentamente e é relativamente pequena, mas, mesmo assim, pode comprometer a aderência das placas cerâmicas ao contrapiso, levar ao gretamento do vidrado e conduzir ao aparecimento de trincas em tijolos, caso as tensões geradas pela deformação contida das peças excedam a resistência limite dos materiais [1-3].
Elementos cerâmicos tais como blocos para alvenaria, placas de revestimento de pisos, fachadas e louças sanitárias estão suscetíveis ao fenômeno físico-químico da expansão por umidade, principalmente quando produzidos a partir de matérias-primas ou condições de processamento inadequadas [4-6]. A EPU, também chamada impropriamente de dilatação higroscópica, tem início assim que a peça entra em contato com o meio ambiente na saída do forno [7] e pode se desenvolver, lentamente, por dezenas de anos após a produção do corpo cerâmico $[8,9]$. A EPU é o resultado da acessibilidade da água, da energia específica, do módulo elástico e das fases presentes na microestrutura do corpo analisado, sendo 
acentuada quando da presença de fases amorfas e vítreas no material $[4,10]$. Após queima, os corpos cerâmicos são constituídos por fases cristalinas, amorfas e vítreas. As fases amorfas, principalmente resultantes da decomposição dos minerais argilosos durante a queima, têm grande tendência a apresentar alta EPU devido à elevada energia superficial e área específica que apresentam. As fases vítreas, produzidas, em geral, pela fusão parcial das matérias-primas utilizadas, possuem baixa área específica, mas em contato com a água há um aumento da área superficial e de sua energia superficial, o que provoca a tendência ao desenvolvimento de EPU. O que evidencia que a influência das matériasprimas e condições de processamento é vital para o controle e obtenção de corpos com baixa EPU [3, 12]. No caso dos revestimentos a EPU pode comprometer a aderência das placas cerâmicas aplicadas em alvenarias e contrapisos e levar ao seu destacamento [5], bem como, contribuir para o gretamento de peças esmaltadas, quando não há o adequado controle do acordo massa-esmalte. Considerando que a EPU natural é um processo extremamente lento, faz-se necessário o desenvolvimento de ensaios laboratoriais a fim de se prever futuros valores da EPU bem como determinar a EPU já sofrido pelo corpo durante sua via útil. A determinação da EPU geralmente é feita através da medição do corpode-prova antes e após requeima. Nesse sentido, também é possível o uso de dilatometria para a determinação da EPU. Essa EPU é considerada a EPU sofrida pelo corpo desde sua fabricação [1]. Para determinação de EPUs potenciais ou futuras do corpo em geral submete-se o corpo a ensaio de autoclavagem (ASTM [13]), imersão em água fervente (ISO [14] e ABNT [15]) ou apenas imersão em água ou exposição ao seu vapor. Estas normas indicam que a EPU máxima para blocos cerâmicos (tijolos) seja de $0,3 \mathrm{~mm} / \mathrm{m}$ $(0,03 \%)$ e que a de revestimentos seja de $0,6 \mathrm{~mm} / \mathrm{m}$ $(0,06 \%)$. Na determinação da EPU por dilatometria as curvas dilatométricas registram as alterações dimensionais das amostras, sejam elas simplesmente ligadas aos valores dos coeficientes de dilatação (térmica), sejam devidas às variedades de fenômenos que podem ocorrer durante o aquecimento, entre os quais reações e transformações estruturais, sinterização, formação de fases viscosas ou líquidas, fluência e eliminação de constituinte, tal como a água adsorvida $[1,8]$. Assim, com a eliminação da água adsorvida no material e limitando a temperatura máxima de aquecimento, para a não ocorrência de alterações microestruturais no material, é possível a determinação da EPU após um ciclo de aquecimento e resfriamento monitorado pela dilatometria. Nesse sentido, é interessante destacar alguns conceitos utilizados na determinação da EPU [8]. EPU "atual" caracteriza a efetiva expansão do corpo cerâmico desde a sua fabricação até o momento do seu emprego, e presta-se a mensuração da influência do referido fenômeno expansivo em falhas do produto acabado. A EPU "potencial" (ou EPU "total") permite a previsão da expansão do corpo cerâmico desde a sua fabricação até o término do que se considere como a vida útil. Ela ocorre desde a queima até a conclusão do processo de envelhecimento, podendo este processo ocorrer de forma natural, muita lenta, ou através de processos acelerados em laboratório [16]. A EPU "futura" é considerada como a expansão que ocorre no corpo cerâmico desde um instante tomado como referência (normalmente o momento em que foi ensaiado pela ocorrência de algum problema) até o término do que se considere a sua vida útil, sendo determinada como a diferença entre a EPU "potencial" e a EPU "atual". Corpos cerâmicos produzidos a partir de materiais inadequados as suas condições de processamento apresentam EPUs "potenciais" extremamente elevadas, o que comprometerá sua vida útil e sucesso da construção em que for utilizado. Assim, evidencia-se a importância do estudo e caracterização de massas cerâmicas produzidas com matérias-primas alternativas, como os resíduos minerais, a fim de avaliar sua adequabilidade para a produção de corpos com pequena tendência a EPU. Deste modo, o presente trabalho tem por objetivo estudar a EPU de corpos cerâmicos confeccionados com resíduos da serragem do granito e do beneficiamento do caulim.

\section{MATERIAIS E MÉTODOS}

Foram utilizados os seguintes materiais: resíduo de granito - resíduo da serragem de granito, resultante do beneficiamento de blocos de granito da Empresa Granfuji S/A - Ind. Com. Imp. e Exp., Campina Grande, PB. Esse resíduo foi caracterizado anteriormente $[17,18]$, sendo constituído basicamente por sílica (61\%), $\mathrm{Al}_{2} \mathrm{O}_{3}(16 \%), \mathrm{CaO}$ e $\mathrm{Fe}_{2} \mathrm{O}_{3}$ (5\%), elevados teores de $\mathrm{K}_{2} \mathrm{O}, \mathrm{Na}_{2} \mathrm{O}$ e $\mathrm{MgO}$, com a seguinte distribuição granulométrica de partículas: 9,94\% (argila), $50,11 \%$ (silte), $35,51 \%$ (areia) e diâmetro médio de 20,53 $\mu \mathrm{m}$ [18]; resíduo de caulim - resíduo do beneficiamento do caulim: derivado da segunda etapa do beneficiamento de caulins primários, procedente do município de Juazeirinho, $\mathrm{PB}$, e cedido pela Indústria de Caulim S/A. Esse resíduo foi caracterizado anteriormente $[18,19]$, sendo constituído por sílica (52\%), $\mathrm{Al}_{2} \mathrm{O}_{3}(39 \%)$, teor de ferro inferior a $1 \%$ e pequenos teores de óxidos fundentes; com uma distribuição granulométrica de partículas de 5,18\% (argila), 18,55\% (silte), 46,92 (areia) e diâmetro médio de 43,96 $\mu \mathrm{m}$; argila - argila proveniente do município de Alhandra, PB, fornecida pela Ind. Armil Minérios Ltda.. Apresenta teores de sílica (53\%), alumina (30\%) e ferro (6\%) e distribuição granulométrica de partículas de 23,20\% (argila), 75,71\% (silte), 1,09\% (areia) e diâmetro médio de 5,07 $\mu \mathrm{m}$ [15].

Foram formuladas composições cerâmicas contendo os resíduos e a argila (Tabela I). As massas produzidas foram caracterizadas através de análise granulométrica por difração de laser (AG), análise química (AQ), análise termodiferencial e gravimétrica (ATD e ATG).

As matérias-primas foram misturadas em moinho de bolas e foram confeccionados corpos-de-prova por prensagem uniaxial (prensa hidráulica Schwing Siwa) a 24,0 MPa com dimensões de $60 \mathrm{~mm}$ x $20 \mathrm{~mm}$ x $5 \mathrm{~mm}$, destinados à determinação das propriedades físico-mecânicas. Aqueles destinados à determinação da EPU foram obtidos com as dimensões de $0,7 \mathrm{~cm} \times 0,7 \mathrm{~cm} \times 5 \mathrm{~cm}$. Após moldagem os 
Tabela I - Composições utilizadas nesse estudo. [Table I - Compositions used in this study.]

\begin{tabular}{cccc}
\hline Composições & \multicolumn{3}{c}{ Proporções matérias-primas (\%) } \\
& Argila & $\begin{array}{c}\text { Resíduo } \\
\text { de granito }\end{array}$ & $\begin{array}{c}\text { Resíduo de } \\
\text { caulim }\end{array}$ \\
\hline I & 70 & 20 & 10 \\
II & 70 & 10 & 20 \\
III & 66,6 & 16,7 & 16,7 \\
\hline
\end{tabular}

corpos-de-prova foram secos em estufa a $110{ }^{\circ} \mathrm{C}$ por $24 \mathrm{~h}$ e submetidos a queima rápida a $1125^{\circ} \mathrm{C}$ e $1150{ }^{\circ} \mathrm{C}$. Em seguida foram submetidos a ensaios de caracterização físico-mecânica. Foram determinadas a absorção de água e o módulo de ruptura à flexão. A absorção de água foi determinada por imersão em água por $24 \mathrm{~h}$ e o módulo de ruptura à flexão (MRF) foi determinado por meio do ensaio de flexão em três pontos com velocidade de deslocamento do braço de aplicação da carga de $0,5 \mathrm{~mm} / \mathrm{min}$.

Para determinação da EPU, os corpos-de-prova foram submetidos aos ensaios de EPU por indução através de autoclavagem a $0,7 \mathrm{MPa}$ por $2 \mathrm{~h}$ que corresponde a uma temperatura de $161{ }^{\circ} \mathrm{C}$, fervura por $24 \mathrm{~h}$ e imersão por período de 60 dias. A determinação da EPU foi efetuada através da técnica de dilatometria (BP Engenharia, RB-3020) antes e após a indução do ensaio da EPU, com requeima com taxa de aquecimento de $150{ }^{\circ} \mathrm{C} / \mathrm{h}$, patamar de $2 \mathrm{~h}$ a $550{ }^{\circ} \mathrm{C}$ e resfriamento natural.

\section{RESULTADOS E DISCUSSÃO}

A Tabela II apresenta os resultados da distribuição de tamanhos de partículas das composições estudadas. A composição I possui diâmetro médio de partículas $33,52 \mu \mathrm{m}$, com cerca de $12,85 \%$ da massa acumulada com diâmetro médio equivalente abaixo de $2 \mu \mathrm{m}$, que corresponde à fração argila, 45,14\% correspondente ao teor de silte, e 41,70\% correspondente ao teor de areia. A composição II apresenta um diâmetro médio de partículas de 46,36 $\mu \mathrm{m}$, apresentando cerca de $9,4 \%$ da massa acumulada com diâmetro médio equivalente abaixo de $2 \mu \mathrm{m}$, que corresponde à fração argila, 34,28\% correspondente ao teor de silte, e 56,08\% correspondente ao teor de areia. Para a composição III observou-se um diâmetro médio de partículas de 38,36 $\mu \mathrm{m}$, com cerca de $10,56 \%$ da massa acumulada com diâmetro médio equivalente abaixo de $2 \mu \mathrm{m}$, que corresponde à fração argila, 40,67\% correspondente ao teor de silte, e 48,73\% correspondente ao teor de areia.

A Fig. 1 apresenta a distribuição granulométrica das composições em estudo. As composições apresentam curvas com comportamento bimodal com larga faixa de distribuição de tamanho de partículas entre $0,1 \mu \mathrm{m} 110 \mu \mathrm{m}$, sendo as maiores concentrações em $90 \mu \mathrm{m}$ e $9 \mu \mathrm{m}$. A composição I

Tabela II - Distribuição do tamanho de partículas das composições estudadas.

[Table II - Particle size distribution of the studied compositions.]

\begin{tabular}{lccc}
\hline Composições & $\begin{array}{c}\text { Argila }(\%) \\
(\mathrm{x}<2 \mu \mathrm{m})\end{array}$ & $\begin{array}{c}\text { Silte }(\%) \\
(2 \mu \mathrm{m}<\mathrm{x}<20 \mu \mathrm{m})\end{array}$ & $\begin{array}{c}\text { Areia }(\%) \\
(\mathrm{x}>20 \mu \mathrm{m})\end{array}$ \\
\hline Composição I & 12,8 & 45,1 & 41,7 \\
Composição II & 9,4 & 34,3 & 56,1 \\
Composição III & 10,5 & 40,7 & 48,7 \\
\hline
\end{tabular}
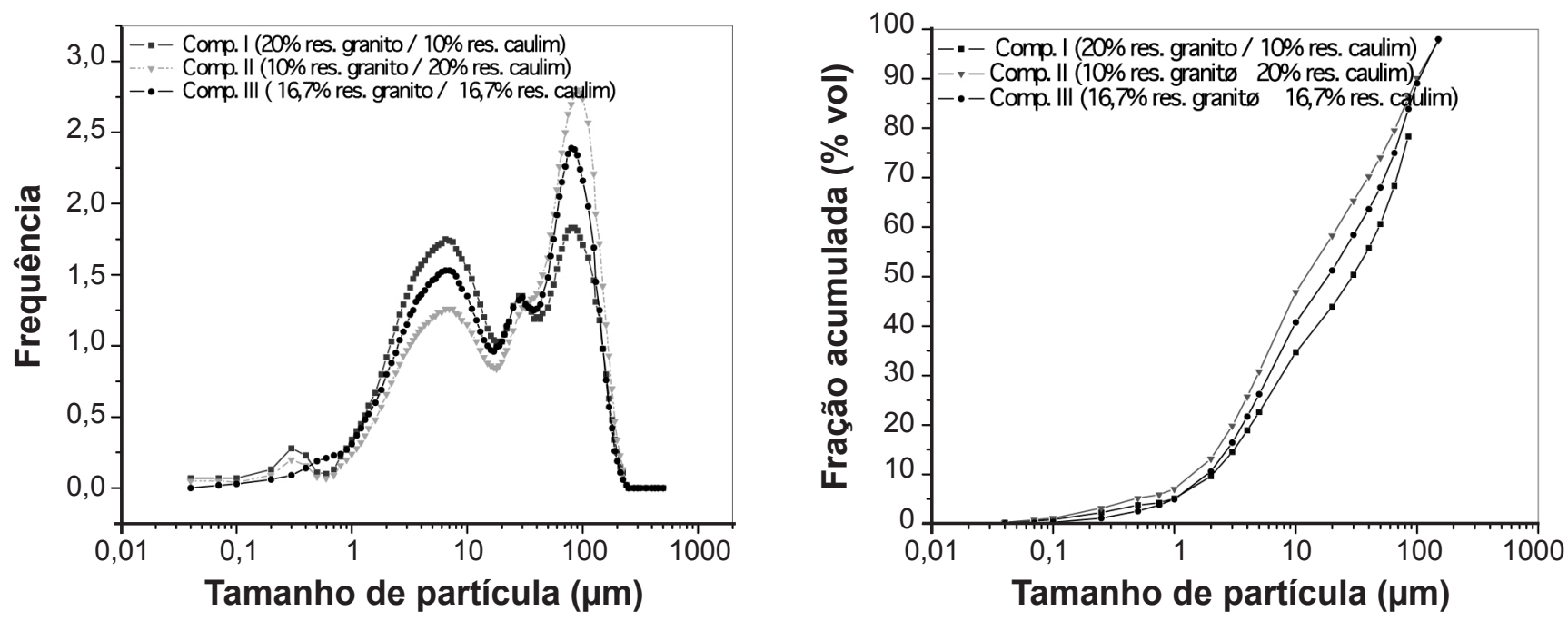

Figura 1: Distribuição de tamanho de partículas das composições. [Figure 1: Particle size distribution of the compositions.] 
Tabela III - Composição química das massas cerâmicas contendo resíduos de granito e de caulim. [Table III - Chemical composition of ceramic masses containing granite and kaolin wastes.]

\begin{tabular}{lccccccccc}
\hline \multirow{2}{*}{ Amostras } & \multicolumn{10}{c}{ Composições (\%) } \\
& $\mathrm{SiO}_{2}$ & $\mathrm{Al}_{2} \mathrm{O}_{3}$ & $\mathrm{Fe}_{2} \mathrm{O}_{3}$ & $\mathrm{MgO}$ & $\mathrm{CaO}$ & $\mathrm{K}_{2} \mathrm{O}$ & $\mathrm{TiO}_{2}$ & Outros & PR $^{\mathrm{a}}$ \\
\hline Composição I & 51,6 & 26,6 & 4,9 & 1,4 & 0,7 & 3,4 & 0,6 & 0,6 & 10,2 \\
Composição II & 51,5 & 28,9 & 4,7 & 1,3 & 0,5 & 3,3 & 0,8 & 0,7 & 8,3 \\
Composição III & 51,6 & 27,1 & 4,7 & 1,3 & 0,9 & 3,2 & 0,7 & 0,6 & 9,9 \\
\hline${ }^{a}$ PR = Perda ao Rubro & & & & & & & & &
\end{tabular}

apresenta diâmetro a $10 \%$ de $1,52 \mu \mathrm{m}$, diâmetro a $50 \%$ de $11,72 \mu \mathrm{m}$ e diâmetro a $90 \%$ de $99,41 \mu \mathrm{m}$.

A Tabela III apresenta as composições químicas das amostras. Os valores obtidos indicam que a composição I apresenta teores de sílica (51\%), $\mathrm{Al}_{2} \mathrm{O}_{3}(26 \%), \mathrm{Fe}_{2} \mathrm{O}_{3}(5 \%)$, $\mathrm{K}_{2} \mathrm{O}(3 \%), \mathrm{MgO}(1 \%)$ e baixos teores de $\mathrm{CaO}$ e $\mathrm{TiO}_{2}$. A composição II apresenta a seguinte constituição: sílica (51\%), $\mathrm{Al}_{2} \mathrm{O}_{3}(28 \%), \mathrm{Fe}_{2} \mathrm{O}_{3}(5 \%), \mathrm{K}_{2} \mathrm{O}(3 \%), \mathrm{MgO}(1 \%)$ e teores de $\mathrm{CaO}$ e $\mathrm{TiO}_{2}$ inferior a $1 \%$. A composição III é constituída por sílica (51\%), $\mathrm{Al}_{2} \mathrm{O}_{3}(27 \%), \mathrm{Fe}_{2} \mathrm{O}_{3}(5 \%), \mathrm{K}_{2} \mathrm{O}(3 \%), \mathrm{MgO}(1 \%)$ e teores inferior a $1 \%$ de $\mathrm{CaO}, \mathrm{TiO}_{2}$. Esses óxidos são muito importantes na formulação cerâmica, pois atuam como agentes fundentes, promovendo uma melhor sinterização das peças.

As Figs. 2, 3 e 4 apresentam as curvas de ATD e ATG das composições. Nas curvas da composição I há picos endotérmicos em torno de $168,3{ }^{\circ} \mathrm{C}$ correspondente à presença de água livre e adsorvida no material; pico endotérmico por volta de $375,9^{\circ} \mathrm{C}$, relacionado à presença de hidróxido de magnésio; grande pico endotérmico em torno de $567,6^{\circ} \mathrm{C}$ referente à presença de hidroxilas da caulinita; pico endotérmico em torno de $950,6^{\circ} \mathrm{C}$ relacionado à presença de carbonato de cálcio e pico exotérmico a $996,8^{\circ} \mathrm{C}$, relacionados à nucleação da mulita. Na curva termogravimétrica observase que a perda de massa total é de 4,4 mg, correspondente as perdas de água livre e adsorvida, hidróxido de magnésio, hidroxilas da caulinita e gás carbônico dos carbonatos.

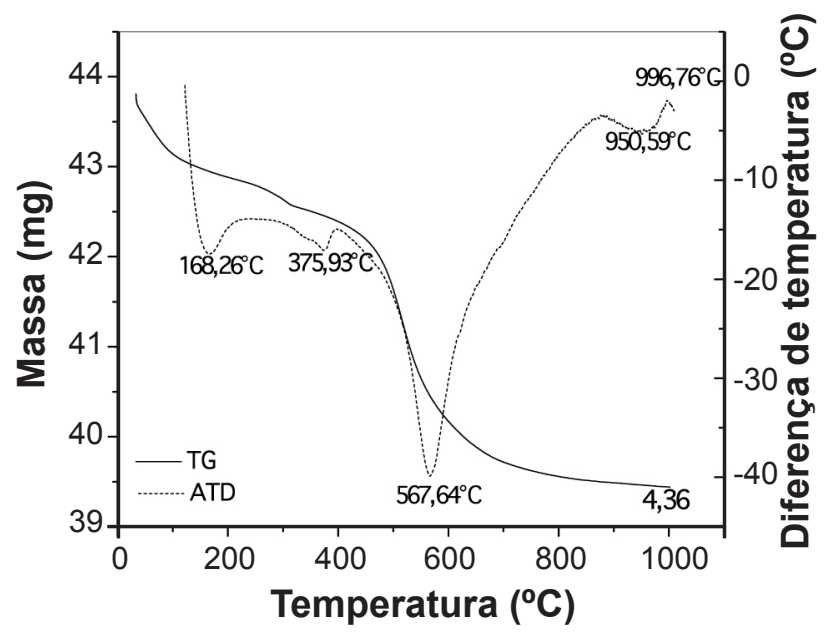

Figura 2: Análise termogravimétrica e térmica diferencial Composição I.

[Figure 2: Thermogravimetric and differential thermal analysis Composition I.]

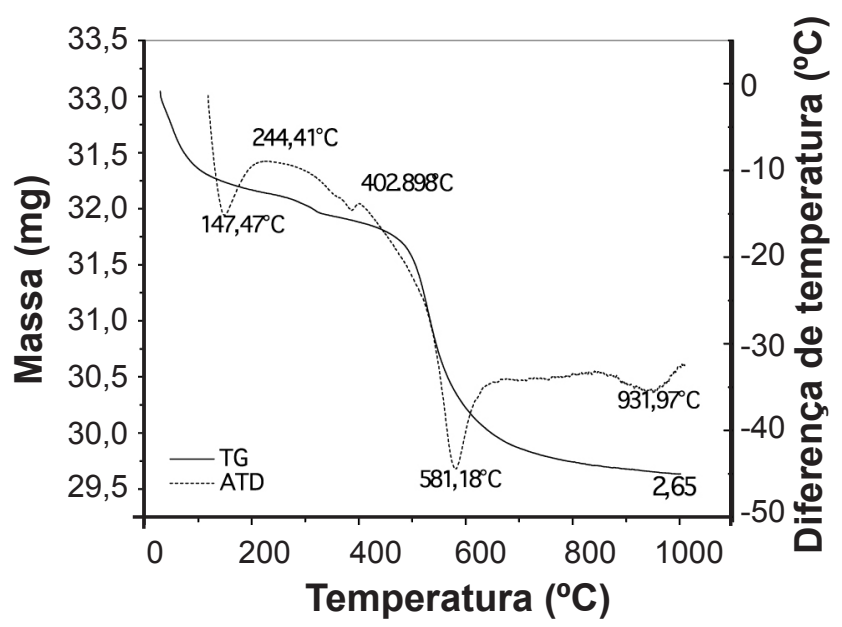

Figura 3: Análise termogravimétrica e térmica diferencial Composição II.

[Figure 3: Thermogravimetric and differential thermal analysis Composition II.]

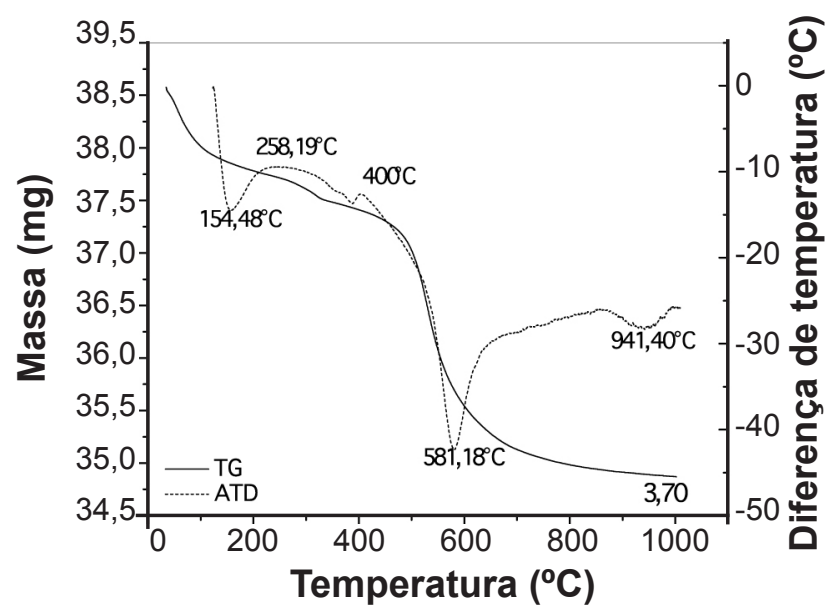

Figura 4: Análise termogravimétrica e térmica diferencial Composição III.

[Figure 4: Thermogravimetric and differential thermal analysis Composition III.]

Na Fig. 3 observa-se pico endotérmico em $\sim 147,5^{\circ} \mathrm{C}$ e pico exotérmico em $\sim 224,4^{\circ} \mathrm{C}$, provavelmente relacionados à presença de água livre e adsorvida no material; pico endotérmico em $\sim 400{ }^{\circ} \mathrm{C}$, relacionado à presença de hidróxido de magnésio; grande pico endotérmico em $\sim 581,2{ }^{\circ} \mathrm{C}$, possivelmente relacionado a presença de 
hidroxilas da caulinita; e pico endotérmico em torno de $932,0{ }^{\circ} \mathrm{C}$ relacionado a presença do carbonato de cálcio. Através da curva termogravimétrica observa-se que a perda de massa total é de $2,7 \mathrm{mg}$, correspondente a perda de água livre e adsorvida, hidróxido de magnésio, hidroxilas e nucleação da mulita.

Na Fig. 4 verifica-se pico endotérmico em $\sim 154,5^{\circ} \mathrm{C}$ e pico exotérmico em $\sim 258,2^{\circ} \mathrm{C}$, provavelmente relacionados à presença de água livre e adsorvida no material; pico endotérmico em torno de $400{ }^{\circ} \mathrm{C}$, relacionado a presença de hidróxido de magnésio; pico endotérmico a $581,2{ }^{\circ} \mathrm{C}$ possivelmente relacionado a presença de hidroxilas da caulinita; e pico endotérmico em $\sim 941,4{ }^{\circ} \mathrm{C}$ relacionada a presença do carbonato de cálcio. Através da curva termogravimétrica observa-se que a perda de massa total é de $3,7 \mathrm{mg}$, correspondente a perda de água livre e adsorvida, hidroxilas e a nucleação da mulita.

A Fig. 5 apresenta os valores de absorção de água e tensão de ruptura a flexão para os corpos-de-prova não autoclavados. Os valores de absorção de água e tensão de ruptura a flexão dos corpos de prova não autoclavados indicaram os melhores resultados a $1150{ }^{\circ} \mathrm{C}$, destacandose a composição I contendo $20 \%$ de resíduo de granito e maior fração argila (Tabela II) a qual apresentou melhores resultados.

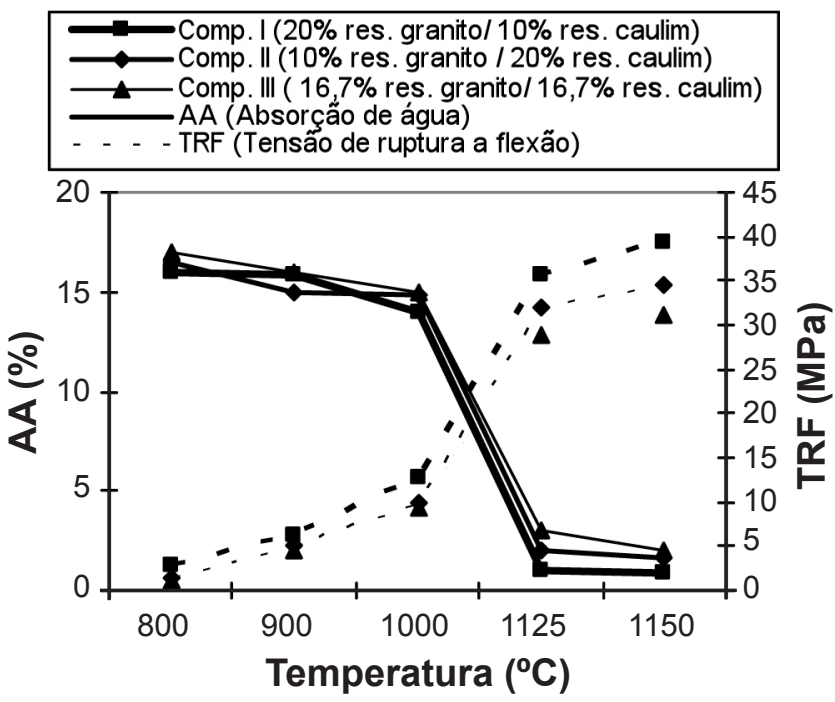

Figura 5: Absorção de água e tensão de ruptura à flexão dos corposde-prova não autoclavados.

[Figure 5: Water absorption and modulus of rupture of non autoclaved bodies.]

Este fato deve-se aos teores de fundentes existentes no resíduo de granito e na argila, responsável por uma melhor sinterização da peça cerâmica, o que contribui para uma redução do volume de poros, conseqüentemente uma redução da absorção de água e um aumento na resistência mecânica. Comparando os resultados de absorção de água e tensão de ruptura a flexão de corpos de prova não autoclavados a $1150{ }^{\circ} \mathrm{C}$, com os estabelecidos pela ABNT
[15], observa-se que estes podem ser classificados como BIIa (semi-grés), BIIb (semi-poroso) e BIII (poroso).

A Fig. 6 apresenta os valores de absorção de água e o módulo de ruptura à flexão dos corpos-de-prova das composições I, II e III submetidas a autoclavagem. Os resultados de absorção de água dos corpos de prova das composições I, II e III submetidos a autoclavagem indicaram uma redução dos valores com o aumento da temperatura de queima, sendo os melhores resultados obtidos a $1150{ }^{\circ} \mathrm{C}$, especialmente para composição I.

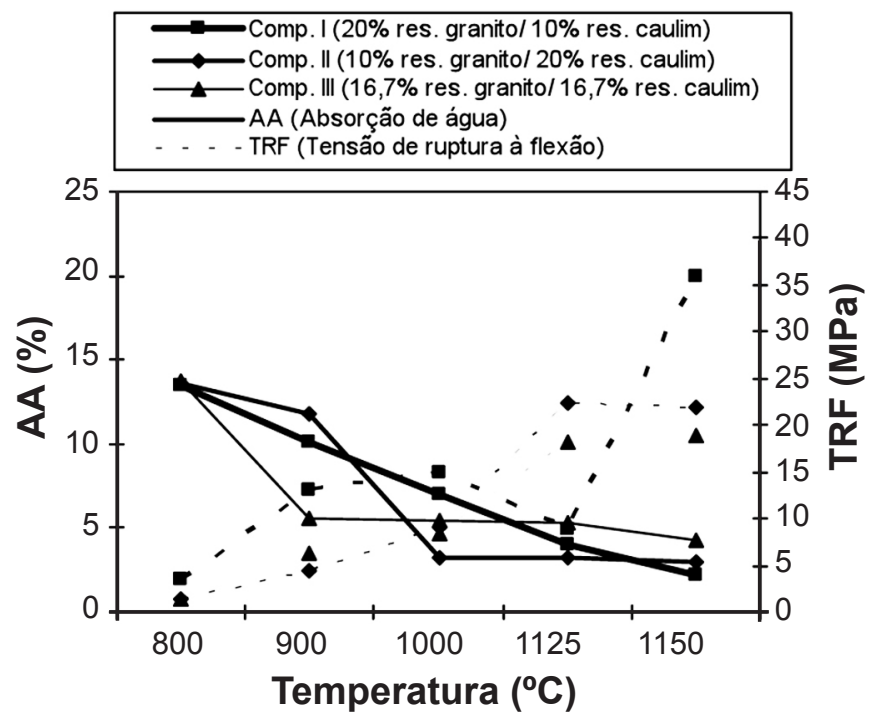

Figura 6: Absorção de água e tensão de ruptura à flexão dos corposde-prova autoclavados.

[Figure 6: Water absorption and modulus of rupture of autoclaved bodies.]

Para a tensão de ruptura a flexão, verificou-se um comportamento semelhante para todas as composições, isto é, houve uma elevação dos valores com o aumento da temperatura, porém para $800^{\circ} \mathrm{Ce} 900^{\circ} \mathrm{C}$ obteve-se resultados inferiores ao estabelecido pela norma. Confrontando os resultados obtidos para a absorção de água e tensão de ruptura a flexão de corpos de prova das composições I, II e III, submetidos a autoclavagem com os valores estabelecidos pela ABNT [15], observa-se que estes podem ser classificados como BIIa (semi-grés) e BIII (poroso). A composição I, com teores de $20 \%$ de resíduo de granito, apresentou melhores resultados de absorção de água e tensão de ruptura a flexão em relação às outras composições. Este fato deve-se principalmente ao teor de resíduo de granito incorporado à massa cerâmica, já que este resíduo é constituído basicamente por feldspato, atuando como agente fundente, e permitindo uma melhor sinterização, obtendose peças cerâmicas com uma estrutura mais organizada no sentido de reduzir o volume de poros, proporcionando um decréscimo nos valores das propriedades de absorção de água devido à redução do volume de poros. Comparando os resultados obtidos para absorção de água e tensão de ruptura a flexão dos corpos de prova autoclavados e sem 
autoclavagem, verifica-se que a composição I, apresentou uma redução na tensão de ruptura à flexão e uma elevação nos valores de absorção de água, enquanto as demais composições apresentaram valores de absorção de água e tensão de ruptura á flexão semelhantes aos valores obtidos para os corpos de prova não autoclavados.

A Fig. 7 apresenta os valores de absorção de água e tensão de ruptura a flexão dos corpos de prova das composições I, II e III submetidas à fervura. Os resultados de absorção de água dos corpos de prova das composições I, II e III submetidas à fervura indicaram uma redução com o aumento da temperatura, obtendo-se os melhores resultados a $1150{ }^{\circ} \mathrm{C}$. Verificou-se ainda que a $800{ }^{\circ} \mathrm{C}$ os resultados obtidos ultrapassaram os valores máximos estabelecidos pela norma ABNT [15], cuja média de valores de absorção de água não deve ser maior que $20 \%$.
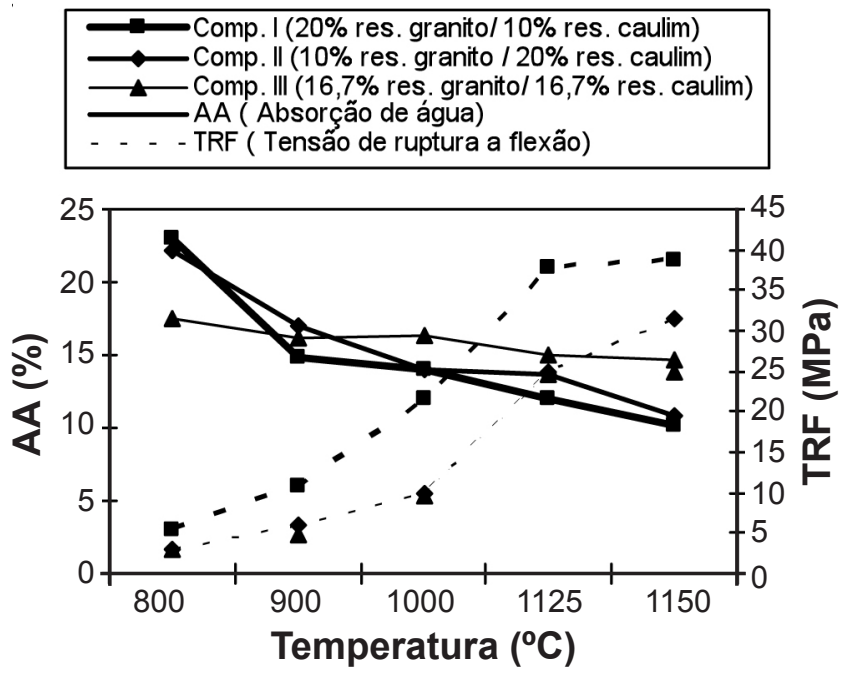

Figura 7: Absorção de água e tensão de ruptura à flexão dos corposde-prova submetidos à fervura.

[Figure 7: Water absorption and modulus of rupture of boiled bodies.]

Os elevados valores de absorção de água verificados a $800{ }^{\circ} \mathrm{C}$ devem-se ao fato que a baixas temperaturas de queima um corpo cerâmico apresenta estrutura altamente pouco cristalina; com o aumento da temperatura de queima a fase líquida diminui a viscosidade preenchendo os vazios entre as partículas, permitindo uma diminuição da porosidade e uma maior densificação da peça, proporcionando uma menor absorção de água. Para a tensão de ruptura a flexão, verificouse que a $800{ }^{\circ} \mathrm{C}, 900{ }^{\circ} \mathrm{C}$ e $1000{ }^{\circ} \mathrm{C}$ todas as composições apresentaram valores inferiores ao preconizado pela ABNT [15]. Enquanto para $1125^{\circ} \mathrm{Ce} 1150^{\circ} \mathrm{C}$ obteve-se valores que permitem classificá-los como BIII (porosos). Observando os resultados obtidos para a absorção de água e tensão de ruptura a flexão dos corpos de prova das composições I, II e III submetidos à fervura e comparando com os valores estabelecidos pela ABNT [15], observa-se que estes podem ser classificados como BIIb e BIII (absorção entre 10 e $6 \%$ e entre 20 e $10 \%$ ) e (tensão de ruptura a flexão entre
30 e $18 \%$ e entre 20 e $15 \%$ ) respectivamente. Comparando os resultados obtidos para absorção de água dos corpos de prova submetidos à fervura com os corpos de prova não autoclavados, verifica-se que após fervura as composições I, II e III apresentaram uma elevação dos valores de absorção de água. Para tensão de ruptura a flexão, apenas a composição I apresentou valores semelhantes, as demais composições apresentaram um decréscimo nos valores após serem submetidos à fervura. Este fato pode explicarse devido à fervura provocar a abertura de poros que se encontravam fechados, promovendo o aumento do volume de poros e conseqüentemente a elevação da absorção de água e, por conseguinte a redução da resistência mecânica.

A Fig. 8 apresenta os valores de absorção de água e tensão de ruptura a flexão para corpos de prova das composições I, II e III submetidos à imersão por 60 dias. Observando os resultados de absorção de água dos corpos de prova das composições I, II e III submetidos à imersão por 60 dias, verifica-se que os melhores valores foram obtidos a $1150{ }^{\circ} \mathrm{C}$, porém para todas as temperaturas empregadas obteve-se valores inferiores a $20 \%$.

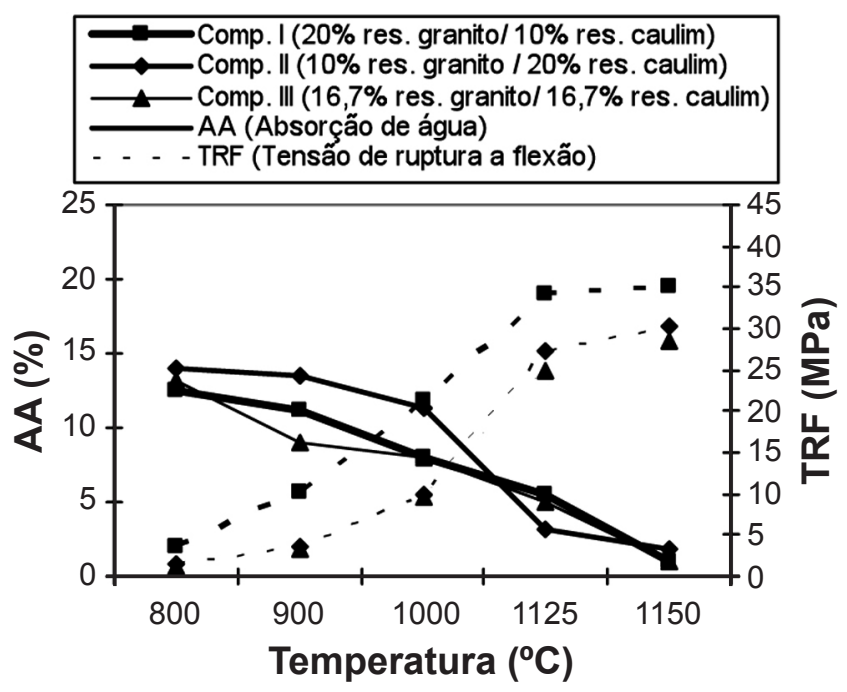

Figura 8: Absorção de água e tensão de ruptura à flexão dos corposde-prova submetidos à imersão por 60 dias.

[Figure 8: Water absorption and modulus of rupture of bodies immersed in water for 60 days.]

Observando os resultados de absorção de água dos corpos de prova das composições I, II e III submetidos à imersão por 60 dias, verifica-se que os melhores valores foram obtidos a $1150{ }^{\circ} \mathrm{C}$; porém, para todas as temperaturas empregadas, obteve-se valores inferiores a $20 \%$. Para a tensão de ruptura a flexão, verificou-se os melhores resultados para 1125 ${ }^{\circ} \mathrm{C}$ e $1150{ }^{\circ} \mathrm{C}$, sendo classificados como BIII (poroso). Comparando os resultados obtidos para absorção de água e tensão de ruptura a flexão dos corpos de prova das Composições I, II e III com os valores estabelecidos pela ABNT [15], verifica-se que estes podem ser classificados como BII b (semi-poroso) e BIII (poroso). Verifica-se que os corpos de prova da composição II apresentaram os 
maiores valores de absorção de água, devendo-se ao fato que à adição de resíduo de caulim, em diferentes teores, proporciona uma tendência de acréscimo nos valores da absorção de água, este comportamento é justificado pelo fato que com a adição deste resíduo ocorrem mudanças na estrutura de poros dos corpos de prova, no sentido de aumentar o volume total de poros deixando os mesmos propensos à acessibilidade da água e, por conseguinte aumentando a absorção de água. Para as composições submetidas à imersão por 60 dias, os corpos de prova da Composição I apresentaram os melhores resultados de absorção de água e tensão de ruptura a flexão em relação às outras composições, este fato deve-se provavelmente ao teor de resíduo de granito incorporado a massa, já que este possui em sua composição elevados teores de fundentes o que permite uma melhor sinterização, obtendo-se peças com menor volume de poros e conseqüentemente menor absorção de água e maior resistência mecânica. Comparando os resultados obtidos para absorção de água dos corpos de prova submetidos à imersão por 60 dias com corpos de prova não autoclavados, verifica-se que os valores obtidos para as composições I, II e III, após imersão por 60 dias foram semelhantes aos valores observados para corpos de prova não autoclavados. Para tensão de ruptura a flexão a composição I apresentou valores semelhantes aos não autoclavados, enquanto as Composições II e III apresentaram após imersão por 60 dias uma redução dos valores de tensão de ruptura a flexão.

A Fig. 9 apresenta os valores de EPU em função da temperatura de queima para os corpos de prova não autoclavados. Observa-se que as composições apresentaram EPU mínima a $800{ }^{\circ} \mathrm{C}$ e $900{ }^{\circ} \mathrm{C}$ para em seguida aumentar gradualmente até atingir um máximo a $1000{ }^{\circ} \mathrm{C}$, para em seguida diminuir com a elevação da temperatura de queima.

Este fato deve-se especialmente, as fases presentes no corpo cerâmico. Em baixas temperaturas um corpo cerâmico

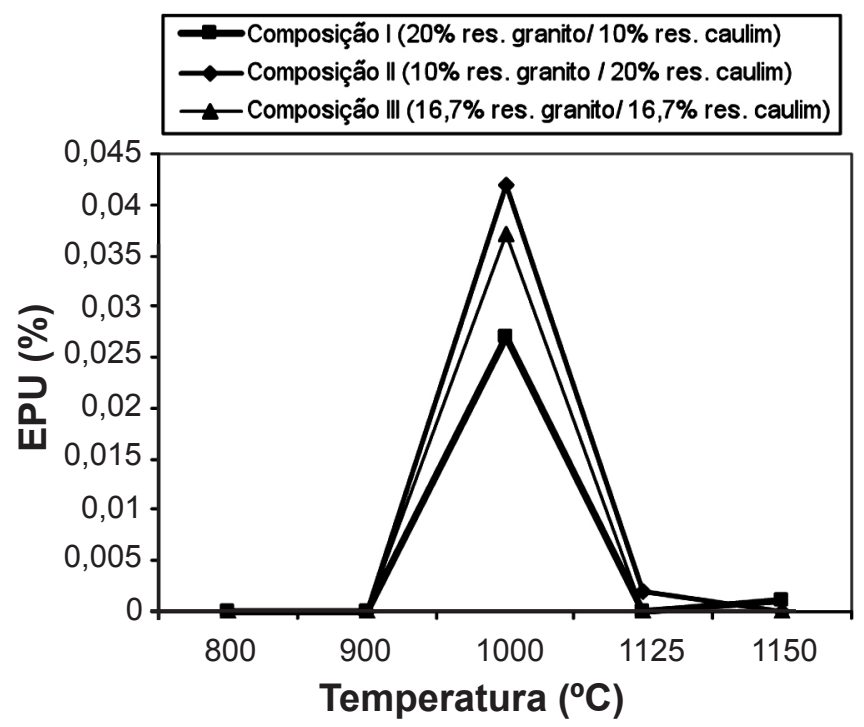

Figura 9: EPU dos corpos-de-prova não autoclavados. [Figure 9: EPU of non autoclaved specimens.] apresenta estrutura altamente porosa, propensa á penetração de água, todavia sem necessariamente a presença de fases amorfas ou vítreas. Com a elevação da temperatura de queima ocorre um gradual aumento do teor de fase vítrea com o preenchimento dos poros e também a formação de fases amorfas (oriundas de reações no corpo cerâmico), com isto, ocorre uma elevação da EPU. Com o contínuo aumento de temperatura, o teor de fase vítrea aumenta ainda mais, havendo a diminuição da área especifica e porosidade, enquanto que as fases amorfas formadas anteriormente transformamse em cristalinas e/ou vítreas, possibilitando que o efeito de redução da porosidade provoque diminuição da EPU. Foram estudadas detalhadamente as reações exotérmicas que ocorrem na caulinita entre $925^{\circ} \mathrm{C}$ e $1110^{\circ} \mathrm{C}$ e as conclusões são adequadas para justificar os maiores valores de EPUs ocorridos à $1000{ }^{\circ} \mathrm{C}$ em massas cerâmicas ricas em caulinita, devido à formação de um espinélio de alumínio e silício com liberação de sílica amorfa a aproximadamente $925{ }^{\circ} \mathrm{C}$ e à transformação do espinélio em mulita, com mais liberação de sílica amorfa na faixa de temperatura entre $1050{ }^{\circ} \mathrm{C}$ e $1100{ }^{\circ} \mathrm{C}$ [20]. No entanto, a formação da fase espinélio só foi observada em caulinitas bem cristalizadas que é o nosso caso. Ao que tudo indica, a única certeza está no fato de haver a formação de uma fase amorfa durante o aquecimento que é responsável pelo pico de EPU.

A Fig. 10 apresenta os valores de EPU em função da temperatura de queima para os corpos de prova das composições I, II e III submetidos a autoclavagem. Observando-se os valores de EPU da composição I, verifica-se que a $800{ }^{\circ} \mathrm{C}$ e $900{ }^{\circ} \mathrm{C}$ os corpos de prova submetidos a autoclavagem apresentaram valores superiores aos especificados pela norma. Para $1000^{\circ} \mathrm{C}$, $1125^{\circ} \mathrm{C}$ e $1150{ }^{\circ} \mathrm{C}$ os corpos-de-prova apresentaram valores de EPU satisfatórios, quando comparados ao valor limite de $0,6 \mathrm{~mm} / \mathrm{m}(0,06 \%)$ para revestimentos cerâmicos.

Observando os valores de EPU dos corpos de prova da composição II, apenas para $1125^{\circ} \mathrm{C}$ obteve-se valor

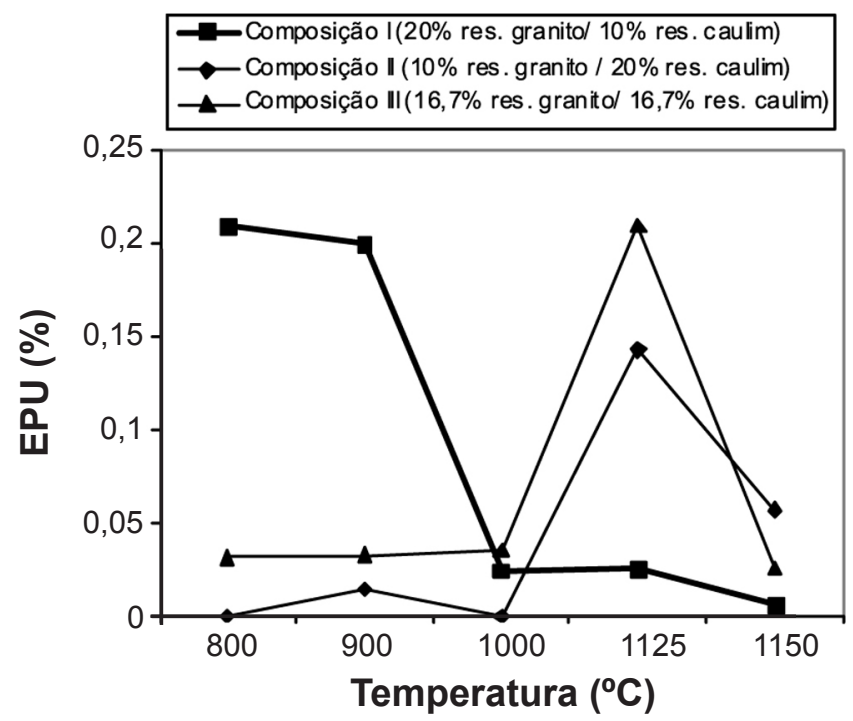

Figura 10: EPU dos corpos-de-prova autoclavados. [Figure 10: EPU of autoclaved specimens.] 
de EPU bastante elevado; para demais temperaturas de queima atingiu-se valores satisfatórios. Para os corpos de prova da composição III, apenas para $1125^{\circ} \mathrm{C}$ obteve-se valores altamente superiores ao recomendado pela norma; para as demais temperaturas os valores atingidos foram inferiores ao estabelecido pela norma $\mathrm{ABNT}$ [15], que estabelece um valor de EPU inferior a $0,6 \mathrm{~mm} / \mathrm{m}(0,06 \%)$ para revestimentos cerâmicos. Comparando os resultados de EPU dos corpos de prova autoclavados, com os resultados de EPU dos corpos de prova não autoclavados, há um acréscimo considerável, isto é uma tendência praticamente universal, pois, a autoclavagem provoca a corrosão da fase vítrea, aumentando a energia superficial e abrindo poros antes fechados aumentando o teor de água adsorvida proveniente de vapores, através da elevação da temperatura e pressão e conseqüentemente, ocorre uma elevação da EPU. Este fato já foi constatado em estudos anteriores [4], os quais, ao se admitir que a ordem de grandeza da EPU em um determinado momento está correlacionada com a quantidade de água adsorvida até o instante considerado, indiretamente é admitido o aumento de tal fenômeno expansivo após a ação da autoclavagem, já que este processo aumenta o teor de água adsorvida proveniente de vapores, pela elevação de temperatura e pressão transmitidas ao corpo cerâmico considerado.

A Fig. 11 apresenta os valores de EPU em função da temperatura de queima para os corpos de prova das composições I, II e III submetidos à fervura. Os corpos de prova da composição I, submetidos à fervura apresentaram valores de EPU superior ao limite de $0,6 \mathrm{~mm} / \mathrm{m}(0,06 \%)$, apenas para $1000^{\circ} \mathrm{C}$; para as demais temperaturas os valores obtidos foram inferiores ao estabelecido pela norma $\mathrm{ABNT}$ [15].

Observando os valores de EPU dos corpos-de-prova da Composição II, os melhores resultados foram obtidos a

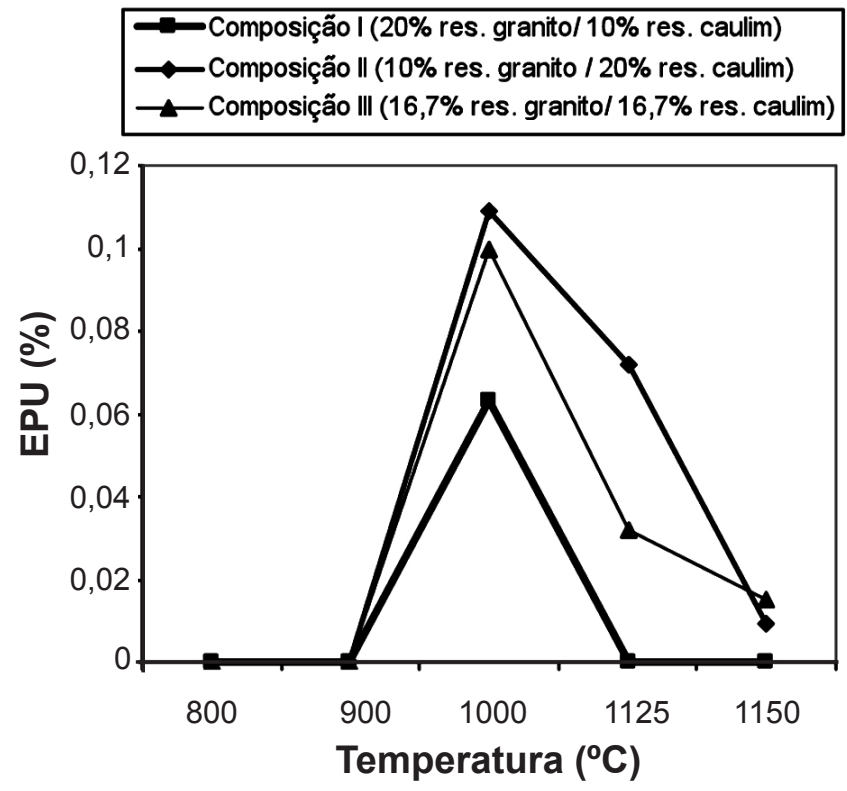

Figura 11: EPU dos corpos-de-prova após fervura. [Figure 11: EPU of specimens after boiling.]
$800{ }^{\circ} \mathrm{C}, 900{ }^{\circ} \mathrm{C}$ e $1150{ }^{\circ} \mathrm{C}$ e apenas para $1000^{\circ} \mathrm{C}$ e $1125^{\circ} \mathrm{C}$ obteve-se valores de EPU considerados elevados quando comparados aos estabelecidos pela norma ABNT [15], que estabelece um valor mínimo de EPU de $0,6 \mathrm{~mm} / \mathrm{m}(0,6 \%)$ para revestimentos cerâmicos. Para os corpos-de-prova da composição III, apenas para $1000{ }^{\circ} \mathrm{C}$ obteve-se valores superiores ao limite de EPU proposto pela especificação. Comparando os resultados obtidos para EPU dos corposde-prova submetidos à fervura com os valores obtidos para corpos de prova não autoclavados, verifica-se que após fervura houve uma elevação da EPU para todas as composições, especialmente para $1000^{\circ} \mathrm{C}, 1125^{\circ} \mathrm{C}$ e $1150{ }^{\circ} \mathrm{C}$, chegandose a obter valores superiores ao especificados, especialmente para as composições II e III. Os valores elevados de EPU para $1000{ }^{\circ} \mathrm{C}$ provavelmente relacionam materiais cuja queima não atingiu a maturação ótima: quando a queima é insuficiente (em temperatura ou tempo), o material apresentase altamente poroso (o que implica alta absorção), mas não contém fases amorfas (que conduzem a elevadas EPUs); com o desenvolvimento da queima, há rearranjos na estrutura, a formação de fases amorfas (resultantes de decomposições de fases presentes no corpo cerâmico) e o início da formação de fase líquida, o que pode contribuir para a diminuição da porosidade (e da absorção), mas também pode promover um aumento gradual da EPU, já que as fases cristalinas são as menos susceptíveis a EPU, e atinge-se, eventualmente, um máximo de EPU. Com o aumento da temperatura de queima, os materiais atingem, ou se aproximaram da maturação: com a consolidação progressiva do corpo cerâmico, tende a haver uma diminuição simultânea da EPU e da porosidade do material, essencialmente por dois motivos: as fases amorfas formadas anteriormente tendem a reagir transformando-se em cristalinas e/ou vítreas; e há o aumento da quantidade de fase líquida no material, que passa a ter um efeito mais significativo na diminuição da porosidade do material (e conseqüentemente na sua absorção de água), proporcionando uma menor acessibilidade à água e, por fim, menor EPU.

A Fig. 12 apresenta os valores de EPU em função da temperatura de queima para corpos de prova das composições I, II e III, submetidos à imersão por 60 dias. Para os corpos de prova da composição I, submetidos à imersão por 60 dias, apenas a $1000{ }^{\circ} \mathrm{C}$ obteve-se valores de EPU superior aos estabelecidos pela norma. Para as demais temperaturas de queima obtiveram-se excelentes valores de EPU.

Observando os valores de EPU dos corpos de prova da composição II, os melhores resultados foram obtidos a $800{ }^{\circ} \mathrm{C}$ e $900{ }^{\circ} \mathrm{C}$, e que a imersão por 60 dias promoveu resultados EPU satisfatórios para todas as temperaturas de queima, satisfazendo as especificações da norma. Para os corpos de prova da composição III, a $800{ }^{\circ} \mathrm{C}$ e $900{ }^{\circ} \mathrm{C}$ obteve-se uma EPU mínima, seguida de uma elevação, chegando a um máximo em $1000{ }^{\circ} \mathrm{C}$ seguida de um decréscimo com o aumento da temperatura, e apenas a $1000{ }^{\circ} \mathrm{C}$ foram obtidos valores de EPU superior ao limite de $0,6 \mathrm{~mm} / \mathrm{m}$ especificado pela norma ABNT [15]. Comparando os resultados de EPU obtidos para os corpos de prova imersos por 60 dias com os resultados obtidos para 


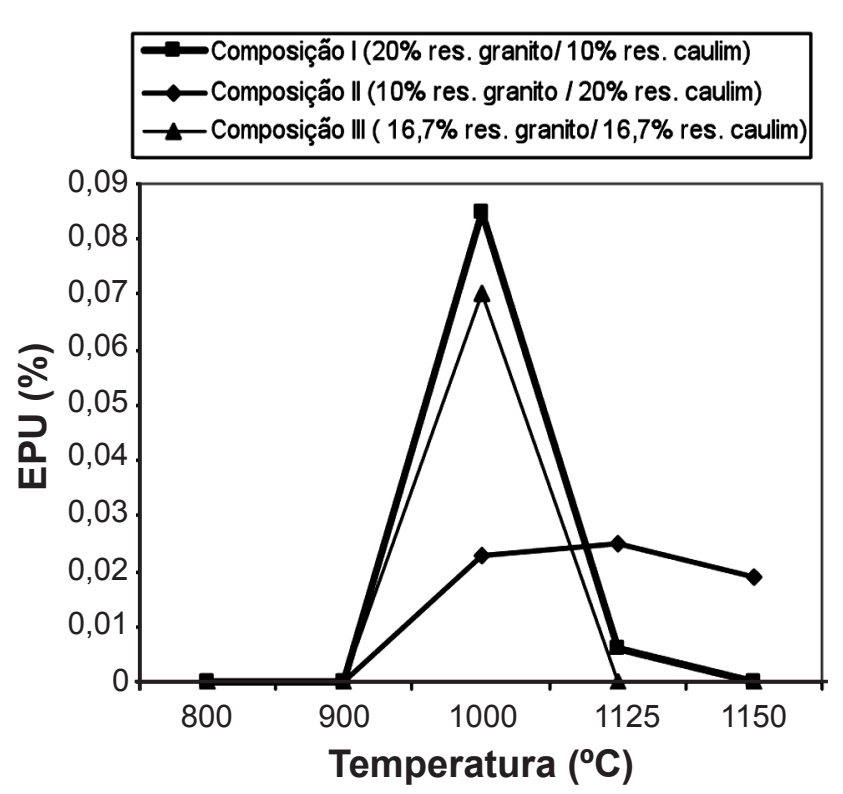

Figura 12: EPU dos corpos-de-prova após imersão por 60 dias. [Figure 12: EPU of bodies immersed in water for 60 days.]

corpos-de-prova não autoclavados, verifica-se que ocorreu uma elevação da EPU a $1000{ }^{\circ} \mathrm{C}$, especialmente para as composições I e III e que a composição II apresentou uma elevação de EPU para $1125^{\circ} \mathrm{C}$ e $1150^{\circ} \mathrm{C}$, porém não superior ao limite de $0,6 \mathrm{~mm} / \mathrm{m}(0,6 \%)$ especificado pela norma ABNT [15].

\section{CONCLUSÕES}

Com o objetivo de estudar a EPU em revestimentos cerâmicos incorporados com resíduos do beneficiamento do caulim e da serragem de granitos como matériaprima alternativa, podemos concluir que: a absorção de água e a tensão de ruptura à flexão dos corpos de prova sem autoclavagem foram inferiores aos valores obtidos após ensaios de aceleração da EPU, sendo os melhores resultados a $1150{ }^{\circ} \mathrm{C}$. Em relação à composição das massas, verificou-se que quando maior teor de resíduo de granito incorporado há uma tendência de reduzir a EPU, especialmente acima de $1000{ }^{\circ} \mathrm{C}$, enquanto aquelas composições com maiores teores de resíduo de caulim proporcionaram valores de EPU mais elevados, principalmente a temperaturas mais baixas.

\section{REFERÊNCIAS}

[1] R. Bowman, Ind. Ceram. 16, 2 (1996) 89.

[2] L. C. Chiari, C. J. Oliveira, C. Monteiro, N. V. Forjaz, E. Biscaro, A. O. Boschi, Ceram. Ind. 1, 1 (1996) 6.

[3] R. R. Menezes, L. F. Campos, G. de A. Neves, H. C. Ferreira, Cerâmica 52, 321 (2006) 1.

[4] J. E. Young, W. E. J. Brownell, J. Am. Ceram. Soc. 42, 12 (1959) 571

[5] R. R. Menezes, A. M. Segadães, H. C. Ferreira, H. S. Ferreira, Cerâmica 49, 310 (2003) 72.

[6] F. C. Z. Júnior, J.W. C.M. Santiago, S. R. M. R. A. Ferreira, Anais VI Cong. Int. Patologia y Recuperacion de Estructuras, Córdoba, Argentina (2010).

[7] R. F. J. Bauer, F. Rago, Ceram. Ind. 5, 3 (2000) 41.

[8] R. R. Menezes, L. F. Campos, G. de A. Neves, H. C. Ferreira, Cerâmica 52, 322 (2006) 114.

[9] R. R. Menezes, L. F. Campos, H. C. Ferreira, H. S. Ferreira, Ceram. Ind. 10, 2 (2005) 27.

[10] A. M. Segadães, M. A. Carvalho, H. C. Ferreira, Ceram. Int. 29, 8 (2003) 947.

[11] M. Y. L. Chew, Constr. Building Mater. 13 (1999) 293.

[12] A. A. Milne, Trans. Brit. Ceram. Soc. 57 (1958) 148.

[13] ASTM C370 - 88(2006) Standard Test Method for Moisture Expansion of Fired White ware Products.

[14] Ceramic Tiles- Determination of water absoption, apparent porosity, apparent relative density and bulk density ISO 10545-6 (2010).

[15] ABNT- Associação Brasileira de Normas Técnicas (ABNT) NBR 13818, Placas cerâmicas para revestimento Especificação e métodos de ensaios, Rio de Janeiro, RJ (1997). [16] L. F. Campos, Estudo da expansão por umidade (EPU) em blocos cerâmicos do Estado da Paraíba, Diss. Mestrado Eng. Quim., UFPB, Campina Grande, PB (2002) 106p.

[17] R. R. Menezes, H. S. Ferreira, G. de A. Neves, H. C. Ferreira, Cerâmica 48, 306 (2002) 92.

[18] A. M. G. D. Mendonça, Uso da técnica de planejamento experimental para otimização de massa cerâmica alternativa para revestimentos, Diss. Mestrado Ci. Eng. Materiais, CCT, UFCG, PB (2007) 64p.

[19] R. R. Menezes, R. R. de Almeida, L. N. L. Santana, G. A. Neves, H. L. Lira, H. C. Ferreira, Cerâmica 53, 326 (2007) 192.

[20] P. S. Santos, Ciência e tecnologia de argilas, Vol. 2 , $2^{\mathrm{a}}$ Ed., Edgar Blucher, S. Paulo, SP (1992).

(Rec. 21/06/2011, Ac. 09/08/2011) 